\section{IRIDOCYCLITIS *}

BY

J. H. DOGGART, M.D., F.R.C.S.

ASSISTANT OPHTHALMIC SURGEON, ST. GEORGE'S HOSPITAL

Although these last twenty years have seen important advances in our knowledge concerning the aetiology of iridocyclitis, ophthalmologists are feeling more bewildered than ever at the problem of causation. Their perplexity is natural. Many of the most striking observations have been of a negative kind, sweeping away barriers which were formerly supposed to define various clinical types, or undermining the validity of long-established diagnostic criteria.

\section{Tuberculous Infection}

Let us consider for a moment the tubercle bacillus, which on the European mainland is often held responsible for 50 per cent. or more of the cases of iridocyclitis, although the average English-speaking ophthalmologist blames it in less than 5 per cent. It has, of course, been recognized for a long time that the ordinary tuberculin diagnostic test was open to the objection that some focus of tubercle was present in almost every person, so as to destroy the significance of a positive reaction. Most people, however, were ready to be convinced by the therapeutic test. When a patient suffering from iridocyclitis of doubtful origin unresponsive to other kinds of treatment derived obvious benefit from a course of tuberculin, he was usually credited with a tuberculous aetiology. No such conclusion is justified if we are to take into consideration the recent researches of Almroth Wright. This authority believes, on experimental evidence, that tuberculin may augment the immunity to other organisms-for example, staphylococci. As for the clinical appearances of tuberculous iridocyclitis, Finnoff reminds us that the classical chronic form characterized by nodules on the iris and "mutton fat" k.p. is by no means the only possible variety. He points out that many cases begin violently, presenting signs indistinguishable from those that occur in other kinds of iridocyclitis.

\section{Syphilis}

Similar difficulties may arise in connexion with syphilis. Not every case of syphilitic iridocylitis displays iridic nodules in association with a rash, a sore throat, and rapid loss of hair. Campbell believed that 70 per cent. of his iridocyclitis cases were syphilitic. He argued that, having had a small painless primary sore, and insignificant secondary manifestations, many of them were unaware of having become infected. The fallacies that arise when the therapeutic test is considered in relation to this disease are at least as formidable as they are in the case of tubercle. More than twenty years ago Terlinck reported three cases of uveitis developing a few days after an injection of arsphenamine or mercury. To-day the Herxheimer reaction is a well-known phenomenon, whether it occurs in a hitherto unaffected eye, or as a rekindling of one that is quiescent, or as the exacerbation of an already established iridocyclitis. It may result from the administration of excessive doses in the early stages of treatment, in which case it is attributed to a large dose of toxin derived from disintegrating spirochaetes ; or the "rezidiv" type may occur when treatment has been abandoned too soon. Other impor-

* Read in opening a discussion in the Section of Ophthalmology at the Annual Meeting of the British Medical Association, Melbourne, 1935. tant considerations are that some syphilitic lesions are very slow to respond to treatment, and that some cases of non-syphilitic iridocyclitis appear to be benefited by arsenical or mercurial preparations. In fact, so far as immediate results are concerned, a case of syphilitic iridocyclitis treated by antisyphilitic remedies may improve, get worse, or remain stationary. The same three possibilities apply with equal validity to nonsyphilitic cases; and so, unless there is clinical evidence of syphilis elsewhere in the body, we must look elsewhere for the means of distinguishing the one from the other. Can a Wassermann reaction be expected to give much help? We know that in a considerable proportion (over 6 per cent. according to Zimmermann) of iridocyclitis patients yielding a positive result the aetiology is other than syphilis. Moreover, the proportion of negative results obtained from undoubtedly syphilitic people is generally admitted to be higher in late than in early cases.

Fifteen years ago I used to be taught that the Wassermann reaction was not a fool-proof pathognomonic test, and that it should be regarded only as a link in the chain of evidence, employed in conjunction with clinical and other data. I was, however, given to understand that it was a strong link, and that although negative results should not be too optimistically interpreted, yet a positive reaction rendered a diagnosis of syphilis highly probable. According to the figures published by Penrose in 1933, my teachers must have unduly flattered this test. Penrose writes:

"The results of testing the blood of mental defeetives for evidence of syphilis have been extremely inconsistent with each other. . . It is noticeable ... that the incidence of positive reactions is on the whole higher when the number of cases tested is small than when it is large. It looks as though investigators usually began testing because they were attracted by a group of cases where positive findings seemed likely to be, or actually were, very frequent. ... The reaction ... is so delicate that it is possible for two observers to make tests on the same specimen, using slightly different techniques, and for them to give bona fide results which differ from one another. For example, 500 specimens of venous blood taken from patients at the Royal Eastern Counties Institute were tested independently by two separate laboratories. Laboratory A returned thirty-eight positives, or 7.6 per cent., and Laboratory B returned 40 positives, or 8 per cent. So far, so good; but when it is found that only in eleven cases, or 2.2 per cent., did the two laboratories agree that the same specimen gave a positive reaction, the result is less satisfactory."

If these researches were to be repeated with similar results by several different observers, the Wassermann reaction would surely cease to have any significance, save for the medical historian.

\section{Focal Sepsis}

Nettleship wrote in 1879 that dental trouble might have some connexion with a group of cases characterized by localized choroido-retinitis and k.p. spots, but the theory of focal infection as an explanation for doubtful cases of iridocyclitis was not commonly put forward until shortly before the Great War. The doctrine of intestinal auto-intoxication was beginning to gain ground in 1912, when Coats made the wise criticism that in almost every case of iridocyclitis this process could be assumed as an explanation, and positively disproved in almost none. More and more people began to look askance at their patients' teeth. Lang thought that about one-third of his cases of iridocyclitis, as well as all his cases of senile central choroiditis, were of dental origin. $\mathrm{He}$ also considered that a similar focus of infection could arise in the 
tonsils, sinuses, skin, or in any mucous membrane, but that teeth were by far the commonest offenders. According to him, inflammatory lesions in the eye were attributable to teeth forty times as commonly as they were to the tonsils. Brown and Irons, on the other hand, blame the tonsils almost as often as they blame the teeth in their first series of 100 cases. Gifford's experience was still further to the detriment of the tonsil, to which he allotted nearly twice as much responsibility for iridocyclitis as he did to the teeth.

\section{Teeth}

Coats's remarks on intestinal auto-intoxication might aptly be repeated with regard to the teeth. Suppose the dental explanation for iridocyclitis were to be attacked on the grounds that, although pyorrhoea affects a large proportion of middle-aged and elderly people, yet iridecyclitis is a comparatively rare condition. Then the obvious retort is forthcoming that among all the million of people who swallow and inhale clumps of tubercle bacilli, only a small proportion provide signs or symptoms of tubercle during life ; and that this fact is not regarded as an argument against the capacity of this bacillus to produce phthisis. Now let us imagine that we are confronted with an obscure case of iridocyclitis in consultation with a colleague who is determined to believe in its dental origin. Externally the teeth appear healthy. $\mathrm{He}$ remarks with perfect justification that dental sepsis is compatible with a normal exterior. $X$-ray photographs are accordingly prepared and show no abnormality. Thereupon he quotes Haden, who has written as follows : "Teeth negative in radiograph may bear as important an aetiologic relation to disease as those which show evident infection." $\mathrm{He}$ prevails upon the patient to undergo removal of the teeth, whereupon one of three things will happen:

(a) The iridocyclitis clears up, and triumphantly vindicates the theory of dental origin.

(b) The eye becomes still more intensely inflamed because, he says, the surgical interference has let loose a flood of toxins or bacilli into the blood stream. (Compare the Herxheimer reaction in syphilitic cases; or the aggravation of a gonococcal iridocyclitis by vigorous prostatic massage.)

(c) No change is observed. He postulates, therefore, a secondary focus of infection which must have arisen in the prostate gland before removal of the teeth. The prostate has now taken over the noxious function of the teeth. Suppose that prostatic palpation by an expert reveals no abnormality. $\mathrm{He}$ reminds us of Benedict's paper, in which we are told that chronic prostatitis may be present without any local signs or symptoms. The patient's prostate is removed. Still the iridocyclitis goes on, but our imaginary friend has a ready explanation. He advises us to consult Zentmayer's paper on the prostate as a focus of infection in ocular inflammation. There we are told that persistence of inflammation after removal of a focus does not absolve that focus from blame. The original focus may have lowered the resistance in such a way that the tissues are now vulnerable by lesser toxins, of a kind that would do no harm in unprepared soil. At this point we are tempted to fling up our hands in despair, and the more so because we are not in a position to disprove any of his arguments. The more we consider aetiology, the more difficult and complicated the problem becomes. Concerning such a hypothetical case, one might speculate with equal plausibility in several directions.

I do not intend to imply that there is no evidence for iridocyclitis of dental origin. There is a great deal of evidence from animal experiments, to which I shall pre- sently refer. Moreover, Paton's 1916 case, in which he obtained a mixed growth of staphylococcus and Micrococcus tetragenus from the anterior chamber may be significant. Other cases might be cited in support of the dental theory, and nobody would maintain that there is anything inherently impossible therein. We know that death from septicaemia has often ensued within a few days of a small skin'scratch in an apparently. healthy subject. The production of an inflammatory reaction in the eye would therefore seem to be well within the range of possible activity for a few organisms or toxins escaping into the blood stream from the teeth or gums.

\section{Objections to Dental Theory}

In spite of the above considerations, I believe the tooth bogy has been absurdly exaggerated. It would require a greater mass of strong clinical and pathological evidence from the human subject to establish dental sepsis as a common cause of iridocyclitis. My main reason for this distrust is the lack of any characteristic clinical type of dental iridocyclitis. Now there is in several of the wellestablished varieties of iridocyclitis a clinical form so characteristic as to be practically pathognomonic, especially, for example, in gonorrhoea, which will be presently considered. It is not pretended that every case of gonococcal iridocyclitis is typical. There are many examples which, as far as the iridic appearances are concerned, might equally well be due to any one of several causes. But there is, I repeat, a type in which that disease can be certainly diagnosed from the eye signs alone. No such claim has ever been seriously made concerning an alleged case of dental iridocyclitis. Admittedly this argument does not disprove its existence, but it does, at any rate, throw some doubt on the contention that teeth are a common source of ocular infection. Here is one more objection to the dental theory. If teeth were really so often to blame, we should expect among ophthalmologists practising under similar conditions at any given period of time in the same geographical area, some general approximate agreement as to the relative frequency of dental as com. pared with other varieties of iridocyclitis. We find no such agreement. On the contrary, we hear most divergent opinions expressed. Some people blame the teeth for nearly all cases of episcleritis, iridocyclitis, and even ordinary senile lens opacities. Others less than a mile distant will scoff at the possibility of any ocular inflammation arising from dental sepsis. The dental theory has now been freely ventilated for nearly a quarter of a century, but in spite of its many enthusiastic supporters (or perhaps in some cases because of them) it has not yet established itself as a common cause of iridocyclitis.

\section{Gonorrhoeal Iridocyclitis}

Gonococci in the blood of a patiént suffering from iridocyclitis weré first isolated in 1901. Brodie reported metastatic eye infections in gonorrhoea as long ago as 1818. Mackenzie remarked nearly a hundred years ago that plastic exudations were more common in gonorrhoeal than in any other variety of iritis. He spoke of

" a profuse effusion of coagulable lymph, filling the pupil, and sometimes falling down in a curd-like form ... into the anterior chamber. In some cases the anterior surface of the iris is covered with lymph as if coated with white paint. The anterior chamber is sometimes almost filled with the effused lymph.... No tubercles are present on the iris. ... Gonorrhoeal iritis is very severe, but yields more promptly to treatment than any of the others, even when the anterior chamber is filled with lymph. After the lymph in the anterior chamber and within the verge of the pupil is absorbed, a cake of it is sometimes seen lying in the centre of the capsule. This is also absorbed." 
Is not this a first-rate description? Kipp, writing in 1880 , likened these coagula to " an opaque lens suspended in the aqueous in front of the pupil." Mackenzie commented on the severe onset in this variety of iridocyclitis. Sometimes it is so violent that a spontaneous hyphaema develops. So far as I know, this feature has never been reported in association with non-gonococcal cases.

Males are affected more than twenty times as commonly as females. I have never been able to observe the characteristic massive coagulation in a female. In the male I have seen it many times. Such an anterior chamber under slit-lamp examination looks as if its circulation were suspended for ever, and yet particles may be seen freely moving about in the aqueous a day or two later. The preponderance of male cases is probably due to one or both of these two factors: $(a)$ the greater length and tortuosity of the male urethra; $(b)$ the accessory sexual glands in communication with the male posterior urethra. Possibly these structures give rise to a substance which in combination with the bacilli elaborates some ocular poison which the bacilli alone could not produce.

It has ofter been stated than gonococcal iridocyclitis is never seen until the onset of arthritic trouble from the same cause. This is inaccurate. Byers noted that ten of his 109 cases showed iritis prior to the involvement of joints. Mackenzie said of this variety of iritis that it may or may not be preceded by synovitis. Goulden mentions a case in which iritis was seen six weeks after the original infection. This interval is exceptionally short. Posterior urethral infection may remain latent for many years. Cobbledick was able to demonstrate gonococci in the centrifugalized urine of a patient whose first and only attack of gonorrhoea had been sustained thirty years previously. Recurrence and eventual bilaterality are other notable features of iridocyclitis from this cause. Lang said that relapses in gonorrhoeal iritis could be prevented by local treatment to the prostate, but most people to-day would say that his statement was too optimistic. Williamson-Noble mentions a case in which removal of the infected prostate prevented a recurrence of iridocyclitis, but does not say how long the man was observed after the operation. I have the impression that atropine irritation is commoner in gonococcal than in other forms of iridocyclitis, and that it is nearly always followed by irritation to all the other mydriatics which may be successively substituted for the atropine. This unfortunate complication may necessitate an iridectomy during the quiescent stage, as a prophylactic measure against secondary glaucoma.

\section{Relative Frequency of Various Cases}

Many writers, including Pockley and Gifford, have drawn attention to the widely varying tables published by those observers who have attempted to estimate the relative commonness of different types of iridocyclitis. We should, of course, expect considerable diversity of results in view of the fact that these researches have been undertaken in various climates, among several social strata, and at different periods. With regard to this last consideration of time, there is overwhelming evidence that syphilitic iridocyclitis has, in most countries, become progressively rarer in the last fifty years. Equally reasonable explanations might perhaps be provided for some of the other discrepancies between the different series. Nevertheless, it is quite certain that many cases would have been classified in several different ways, according to which clinic they had happened to attend. The enormous influence assigned to tubercle in European countries requires no further comment. Teeth are insignificant in some series and predominant in others. Cobbledick and
Dunn found that gonorrhoea was by far the commonest cause of iritis in their male patients. My own experience agrees with theirs. In the second series of Irons and Brown, numbering 100 cases, only one was regarded as gonococcal. Most writers confess ignorance of the cause in 10 to 40 per cent. of their cases, but Irons and Brown in their first series of 100 were only once baffled. Halliday, on the other hand, frankly admits that the cause was undetermined in 70 per cent. of his series of over 200 cases.

\section{Matters of General Agreement}

Although increase in knowledge has apparently added to the difficulties of diagnosis, there has, on the whole, been a notable advance in the last twenty years. The average ophthalmologist of to-day may admit uncertainty as to the main cause of iridocyclitis in a higher proportion of his cases than would have seemed obscure to his predecessor. The number of his positive errors in diagnosis, however, will be smaller, provided that he cares to avail himself of other observers' collective experience. In spite of many conflicting opinions, the number of well-supported clinical observations goes on accumulating. Non-traumatic iridocyclitis as a complication or sequel, whether rare or common, is by general consent associated with the following conditions: gonorrhoea, syphilis, tubercle, herpes zoster, typhoid, influenza, septicaemia, malaria, leprosy, and diabetes. A few observers (Forster, etc.) have reported it as arising in the course of rheumatic fever, but, in the absence of repeated confirmation, it is safer to regard such isolated cases as coincidental. Halliday is convinced of its connexion with arthritis deformans. Gilbert and von Herrenschwand have described a rare but distinct group of " ophthalmia lenta " cases, in which subacute endocarditis leading to progressive anaemia, splenic enlargement, fever, and malaise is associated with bilateral hypopyon iridocyclitis in young adults. Now in a considerable proportion of iridocyclitis cases the most careful investigations will reveal none of the abovementioned causes. Even if the list of causes be extended to include tropical varieties, and such debatable factors as gout and rheumatism, there will still be a large group whose aetiology has yet to be determined. It is not surprising that such a group should inspire a vast quantity of careful research which will continue until the problem is solved. Unfortunately that happy conclusion is not yet in sight, nor can it be hastened by the extravagant claims that have often been put forward.

\section{General Theories of Causation}

In the absence of exact knowledge the residual group of cases to which I have just referred has undergone manifold interpretation, but I shall mention only three schools of opinion:

1. Those who consider that tubercle accounts for them.

2. The focal sepsis believers, among whom the teeth are most commonly blamed. Other organs or tissues suspected are the tonsil, nasal sinuses, gall-bladder, genito-urinary tract (non-venereal infections), appendix or other parts of the alimentary tract, and skin.

3. Those who confess uncertainty and await further knowledge.

Before mentioning the animal experiments individually, I shall briefly recapitulate what appear to be the main factors in the production of metastatic iridocyclitis according to modern theories:

1. A noxious substance, which may consist of (a) bacteria ; (b) bacterial endotoxins or exotoxins ; (c) some end-product of reaction between the bacteria and its host's tissues; or (d) material not derived from bacteria at all. 
2. The conveyance of such a substance from its focus to the eye by blood vessels or lymphatics.

3. Alterations in the eye itself, rendering it more susceptible to infection. One example of such an alteration is the trauma which can precipitate an attack of interstitial keratitis (see Hildebrand, etc.). This is, of course, a crude example, and no doubt $\backslash$ there are innumerable possibilities of subtler eye changes to which the name allergic sensitization is commonly applied.

4. Adaptation on the part of the organism so that it becomes more noxious to the uveal tissue. The resulting changes, of course, may be far too delicate to allow detection by any microscopical or cultural method within range of our technique. This hypothetical adaptation is known as elective localization.

\section{Animal Experiments}

Some of the recent work recalls Wessely's corneal experiment. When this observer injected heterologous serum into the cornea, he at once noted a moderate reaction lasting for two weeks. Two weeks later, injection of the other eye with the same antigen evoked a violent inflammatory reaction in the substance of the cornea (" keratitis anaphylactica"). Levy, Steinbugler, and Pease tried to produce iritis in rabbits by injecting bacteria into lymphatic vessels, but all the animals died without showing eye lesions. Uveitis in animals has been reported as a sequel to the following operations, performed chiefly on rabbits.

\section{A. Intraocular injection of}

(1) Toxins extracted from staphylococci and streptococci (Woods and Stoddard).

(2) Glycerinated tuberculin after previous sensitization (Lagrange)

(3) Foreign protein after previous general sensitization by, intravenous injection of the same substance (Brown).

(4) "Non-virulent" organisms-for example, Staphylococcus albus, into the opposite eye (Marchesani).

B. Intravenous injection of

(1) Cultures of streptococci and other pathogenic organisms (Rosenow, Haden, Meisser and Gardner, Brown and Dummer).

(2) "Non-virulent" organisms (von Szily).

(3) Toxins derived from ferment-producing bacteria-for example, $B$. prodigiosus (Guillery, Woods).

(4) Foreign protein after previous sensitization of the eye by intraocular injection of the same substance (Brown).

(5) Yeast (Stock) and various proteins (von Szily).

The last item on this list naturally evokes these questions: If uveitis can really be produced by the intravenous injection of a foreign protein chosen at random, are not most of these other experiments irrelevant or inconclusive? Are we not compelled to suppose that experimental uveitis has time after time been attributed specifically to toxins and bacteria when it was in fact merely a result of non-specific protein shock? According to Rosenow's results, however, the problem is not so simple as that. He reported that when 222 rabbits were injected with streptococci from 85 cases of acute appendicitis only 1 per cent. developed eye lesions ; on the other hand, ocular inflammation arose in 41.6 per cent. of 272 others injected with organisms taken from the various infective foci of eighty-seven patients suffering from uveitis. Haden's results were of similar import. Nickel went further. In his experiments, streptococci selected from acute foci gave twice as many positive results as did those that were taken haphazard. Rosenow had already published work showing that the incidence of eye trouble from the injection of certain organisms could often be greatly enhanced by the repeated passage of these organisms through animals. To this form of adaptation he applied the term " elective localization." It is not yet possible to assess the value of all these experiments and the extent to which animal results can be expected to illuminate human pathology ; but, whatever their ultimate significance may be, they have so far failed to provide us with a cure for the obstinate cases.

\section{Heterochromic Cyclitis}

One example of mysterious aetiology is provided by a group of cases in which, as the above name implies, bleaching of the iris and limitation of the disease to one eye are the characteristic features. In this type of iridocyclitis pain is conspicuously absent. Synechiae are unusual. Ciliary flush is often lacking and complicated cataract is almost invariable. The dots of k.p. tend to become so large that they can easily be seen without the aid of a loupe, although they do not attain to the huge size of tuberculous " mutton fat" deposits. The affection seems to be equally common among the two sexes. Lutz thought that brunettes were more susceptible than blondes. Fuchs expressed the opinion nearly thirty years ago that the heterochromia precedes and predisposes to the cyclitis. Recently Williamson-Noble has speculated as to whether cyclitis may arise from deprivation of trophic sympathetic fibres. I am aware that paralysis of the cervical sympathetic in association with heterochromia is not unknown, but I suspect that it must be exceedingly rare. I have seen numerous cases of heterochromic cyclitis, but none exhibited Horner's syndrome. It is, however, certain that this form of cyclitis is insidious, and that its early stages might well escape notice in perfunctory examination. Moreover, there is no need to credit heterochromia with any pathognomonic significance. Bleaching is a well-recognized phenomenon in many cases of glaucoma, and in iridocýclitis from various causes, especially herpes zoster. It is not uncommon as a senile change in the absence of any disease, and may effect one eye more than the other, or even exclusively. Senile scattering of the pigment layer is almost universal, but extensive and irregularly distributed atrophy of the mesodermic layers is by no means rare. When marked bleaching of one iris is associated with numerous pigmented spots on the back of the cornea, and the presence of broken, frayed iris fibres near the pupillary border, iridocyclitis is closely simulated. The proper use of a slitlamp will immediately settle any doubt in the diagnosis of such a case. Heterochromia may also occur as a congenital condition or as a result of trauma.

\section{Obstinate Iridocyclitis in Females}

Some of the most distressing cases in ophthalmic practice are those middle-aged or elderly women who suffer from recurrent attacks of iridocyclitis without any obvious cause. In nearly every case of this kind the second eye is sooner or later implicated. Although pain is not, as a rule, very severe, there is in most instances progressive damage to sight from posterior synechiae, and from obscuration of the pupil by plastic exudate. Peripheral anterior synechia is another dangerous complication to which prolonged mydriatic treatment renders these patients liable. Often it will be found that the patient's teeth had all been removed many years before, and that the most careful search for a septic focus or general disease proves unfruitful. Every ophthalmic surgeon, however resourceful, encounters such cases, in which his utmost efforts meet with failure. The fact that this type of case occurs far more often in women, and that it most commonly begins during or after the menopause, has been noted by Jocqs, Galezowski and Berche, and others. Perhaps its development is facilitated by debris from the involuting sex organs. 


\section{Treatment}

Apart from the recognized use of heat, mydriatics, and other local remedies in iridocyclitis, most people would favour the elimination of a manifest septic focus unless they had reason to believe that this procedure was unduly mutilating, or constituted a danger to life. When no septic focus is detected, and every test has proved negative in a patient suffering from repeated attacks, a choice of general treatments has to be made. Salicylates are still regarded as valuable by a number of clinicians. Injections of milk have recently been tried, with the object of stirring up the resistive powers of the patient by mild protein shock. Some advocates of this method believe that any success attained by the use of tuberculin, whether in tuberculous or in non-tuberculous cases, should be ascribed to the protein as such, rather than to any special property of the vaccine. I have had the opportunity to examine a number of recurrent iridocyclitis patients treated with milk, but I was not convinced that any of them derived benefit. To become thoroughly established, this or any other new form of iridocyclitis treatment must supply unmistakable results over a long period, because this is a disease whose severity is extremely variable. Patients with iridocyclitis of undiscovered origin do not necessarily get recurrences. I have notes of several such cases in which periodical observation every few months has revealed no relapse for periods varying between three and six years. Admittedly one cannot guarantee that they will never recur; but it is in the meantime permissible to point out that, if this prolonged immunity had happened to follow upon curettage of the cervix, tonsillar enucleation, or removal of teeth, they might have been claimed as further examples of iridocyclitis resulting from focal sepsis. During convalescence from influenza there is a characteristic bilateral iridocyclitis which responds very well to treatment, and does not recur.

\section{The Need for Clinical Detail}

New discoveries in bacteriology, biochemistry, and other sciences relating to medicine do not lessen the need for care in clinical scrutiny. Let us by all means make full use of the pathologists and other special workers who are readily available in every large town. There is, however, a danger that the indiscriminate request for a Wassermann reaction, differential white cell count, tuberculin test, analysis of excretions, and $x$-ray photography, at the outset of every case of iridocyclitis, may come to be regarded as more important than the proper routine examination of the eye itself. Patients are often subjected to a long series of laboratory investigations without having had their vision recorded. I have seen pretentious remedies prescribed for people whose second eye displayed large dots of undetected k.p. Sir Walter Langdon-Brown, in the course of his Sir Charles Hastings Lecture this year, has rightly reminded us that " bacteriology has not brought us all the gifts anticipated." $\mathrm{He}$ is justified in complaining that "some laboratory teachers seem to regard medical practice as only suitable for their thirdclass man." Happily there are signs that the prestige of clinical work is no longer on the wane. There are probably more people to-day than there were ten years ago who realize that the manipulation of a pipette is not necessarily more difficult than the proper use of the ophthalmoscope, and that unfamiliarity with Donnan's hypothesis is less to be deplored than slovenliness in clinical work. We should not forget what shrewd discoveries were made by clinicians in former days. Tabes came to be regarded as syphilitic long before the emergence of the spirochaete. Galezowski wrote that " rheumatic iritis non-gonorrhoeal is a rare thing," as long ago as 1867, at which time the gonococcus was unknown. The examination of the living eye will continue to yield fresh secrets. Only a few years ago Vogt was by such methods enabled to demonstrate the important and interesting capsulo-cuticular subdivision - of glaucoma. Distinctive types of iridocyclitis are already recognized in several diseases, and clinical vigilance is still needed if we are to achieve further differentiation.

\section{Bibliography}

Anderson: Med. Journ. of Australia, 1926, ii, 73.

Back: Klin. Monats. f. Augenheilk., 1927, lxxviii, 316.

Beaumont: British Medical Journal, 1910, ii, 1911.

Benedict: Amer. Journ. Ophthalmol., 1920, iii, 860 ; Arch. of Ophthalmol., 1921, 1, 560 ; ibid., 1927, 1vi, 116.

Brown, Edgar: Med. Journ. of Australia, 1928, i, 124.

Brown: Amer. Journ. Ophthalmol., 1932, xv, 19.

Brown and Dummer: Arch. of Ophthalmol., 1929, ii, 573.

Brown and Irons: Trans. Amer. Ophthalmol. Soc., 1915-16, xiv, Part 2, 495.

Butler: British Medical Journal, 1910, ii, 573 ; ibid., 1911, i, 804.

Byers: Studies from Royal Victoria Hospital, Montreal, 1908-10, No. 2.

Campbell: British Medical Journal, 1910, ii, 231.

Coats: Ibid., 1912, ii, 1017.

Cobbledick: Ophthalmoscope, 1912, x, 703.

Daviès: Brit. Journ. Ophthalmol., 1917, i, 608.

Dunn: British Medical Journal, 1910, ii, 1564 .

Elschnig: Klin. Monats. $f$. Augenheilk., 1925, lxxiv, 783.

Finnoff: Amer. Journ. Ophthalmol, 1931, xiv, 127.

Forster: British Medical Journal, 1903, i, 543.

Friedenwald: Arch. of Ophthalmol., 1896, xxv, 191.

Friedenwald and Rones: Arch. of Ophthalmol., 1931, v, 175.

Fuchs: Zeit. f. Augenheilk., 1906, xv, 191; Trans. Internat. Med. Congress, London, 1913, Sect. Ophthalmol., Part II, 1.

Galezowski: Gaz. des Hop., 1867, xl, 17.

Galezowski and Berche: Receuil d'Ophtalmol., 1911, xxxiii, 97.

Gifford: Amer. Journ. Ophthalmol., 1931, xiv, 100.

Gilbert: Arch. f. Augenheilk., 1925, xcvi, 119.

Goulden: Royal London Ophthalmic Hospital Reports, 1914, xix, 328.

Griffith: Trans. Ophthalmol. Soc. U.K., 1900, xx, 83.

Guillery: Arch. f. Augenheilk., 1911, xlviii, 242; ibid., 1914, lxxviii, 11.

Haden: Arch. Int. Med., 1923, xxxii, 828.

Halliday: Med. Journ. of Australia, 1920, ii, 279 ; ibid., 1930, ii, 170 ; ibid., 1933, i, 474.

von Herrenschwand: Klin. Monats. f. Augenheilk., 1929, lxxxiii, 419.

Hildebrand: Inaug. Diss., Leipzig, 1913.

Igersheimer: Arch. f. Ophthalmol:, 1922, cix, 265.

Irons and Brown: Journ. Amer. Med. Assoc., 1923, Ixxxi, 1770 ; ibid., 1926, Ixxxvii, 1167.

Irons, Brown, and Nadler: Journ. Infect. Dis., 1916, xviii, 315.

Jennings: Ophthalmology, 1909, vi, 52.

Jocqs: La Clin. Ophtalmol., 1922, xi, 243.

Kipp: Med. Record, 1880, xvii, 717 .

Klauder: Arch. of Ophthalmol., 1932, vii, 268.

Kummel: Arch. f. Ophthalmol., 1910, 1xxvii, 393

Lagrange: Arch. d'Ophtalmol., 1923, xl, 670 ; ibid., 1924, xli, 80 ; La Tuberculose du Tractus Uvéal, Paris, 1924.

Lang: Lancet, 1913, i, 1368 ; Proc. Roy. Soc. Med., 1916, x, Part 3 Section Ophthalmol., 42 .

Levy, Steinbugler, and Pease: Journ. Amer. Med. Assoc., 1917, lxix, 194.

Lewis: Ibid., 1919, Ixxiii, 1132.

Lutz: Zeit. f. Augenheilk., 1908, xix, 208.

Mackenzie: Diseases of the Eye, third edition, 1840, p. 475.

Marchesani: Arch. f. Augenheilk., 1929, c-ci, 606.

Meisser: Journ. Amer. Dent. Assoc., 1925, xii, 554.

Meisser and Gardner: Ibid., 1922, ix, 578.

Moore: Amer. Journ. Ophthalmol., 1931, xiv, 110

Nettleship: British Medical Journal, 1876, ii, 617; Royal London Ophthalmic Hospital Reports, 1879, ix, Part 2, 182.

Nickel: Journ. Amer. Med. Assoc., 1926, Ixxxvii, 1117.

Ormond: British Medical Journal, 1912, ii, 1020.

Ormond: British Medical Journal, 1912, ii, 102

Penrose: Mental Defect, London, 1933, p. 38.

Poynton and Paine: Trans. Ophthalmol. Soc. U.K., 1903, xxiii, 39.

Rosenow: Journ. Amer. Med. Assoc., 1915, lxv, 1687; Trans. Amer. Acad. Ophthalmol. and Oto-laryngol., 1927, p. 41.

Rosenow and Nickel: Amer. Journ. Ophthalmol., 1932, xv, 1.

de Schweinitz: Trans. Internat. Med. Cong., London, 1913, Sect. Ophthalmol., Part II, 7; Au Sujet de Certaines Manifestations Oculaires des Foyers Infectieux.

Shorney: Med. Journ. of Australia, 1927, ii, Supplement, 208.

Stock: Beiträge zur pathologischen Anatomie und zur allgemeinen Pathologie, 1908, xliii, 4700.

von Szily: Trans. Internat. Cong. Ophthalmol., Amsterdam, 1929, ii, 533 ; Klin. Monats. f. Augenheilk., 1930, Ixxxv, 21.

Terlinck: Zeit. f. Augenheilk., 1914, xxxi, 500.

Wessely: Münch. med. Woch., 1911, lviii, 1713.

Weve: Arch. f. Augenheilk., 1923, xciii, 14.

Williamson-Noble: Lancet, 1932, i, 1293, 1345

Woods: Arch. of Ophthalmol., 1916, xlv, 557 ; ibid., 1916, xlv, 451.

Woods and Stoddard: Ibid., 1916, xlv, 321.

Zentmayer: Journ. Amer. Med. Assoc., 1926, lxxxvii, 1172.

Zimmermann: Arch. of Ophthalmol., 1924, liii, 549. 